\title{
AVALIAÇÃO TÉRMICA DO PROCESSO DE SECAGEM DE MISTURAS DE GRAVIOLA E LEITE EM SECADOR DE LEITO DE JORRO
}

\author{
T. M. DELMIRO ${ }^{1}$, I. P. MACHADO ${ }^{1}$, M. F. D. de MEDEIROS $^{2}$ \\ ${ }^{1}$ Universidade Federal do Rio Grande do Norte, Departamento de Engenharia Química \\ ${ }^{2}$ Universidade Federal do Rio Grande do Norte, Departamento de Engenharia Química \\ E-mail para contato: thalita.marreiro@hotmail.com
}

\begin{abstract}
RESUMO - Neste trabalho estudou-se os requerimentos térmicos do processo de secagem de misturas de graviola e leite em leito de jorro com partículas inertes. Foram efetuados os balanços de massa e de entalpia no secador e a partir destes realizou-se a análise térmica de secagem, calculando-se as perdas e a eficiência térmica do processo. A partir dos dados psicrométricos foi avaliada a saturação relativa do ar na saída do secador. A maior taxa de secagem $(0,142 \mathrm{~g} / \mathrm{s})$ e maior eficiência térmica $(60,38 \%)$ foi observada no ensaio realizado nas condições de maior concentração de leite e menores temperatura, tempo de intermitência e velocidade do ar. $\mathrm{O}$ ar de exaustão apresentou elevado potencial energético e baixo grau de saturação.
\end{abstract}

\section{INTRODUÇÃO}

A secagem é um processo bastante utilizado na indústria e possibilita a obtenção de produtos com boas características de conservação, além de facilitar o seu armazenamento e transporte.

$\mathrm{Na}$ secagem acorrem dois fenômenos: a transferência de calor e de massa. A transferência de calor é observada no aquecimento do produto e no processo de mudança de fase, através da vaporização do líquido. A transferência de massa é a passagem do líquido ou vapor que passa do alimento para a atmosfera. O controle da secagem é dependente das condições internas de transferência de massa (características do sólido) ou condições externas (velocidade e temperatura do ar de secagem) (CRUZ, 2013).

Dentre os secadores de pastas e suspensões, o leito de jorro com partículas inertes vem se destacando e tem sido objeto de diversas pesquisas, por apresentar altas taxas de transferência de calor e massa, como também por ser um equipamento com baixo custo de valor inicial e operacional. Dentre as pastas e suspensões secadas, destacam-se as polpas de frutas, o leite e pastas de legumes e hortaliças. Considerando que no leito de jorro são requeridas elevadas vazões de ar para manutenção da estabilidade fluidodinâmica do secador, importante se faz quantificar os requerimentos térmicos necessários e as perdas para o ambiente visando-se a otimização energética do processo. Neste trabalho realizou-se a análise térmica do processo de secagem da polpa de graviola com adição de leite no secador de leito 


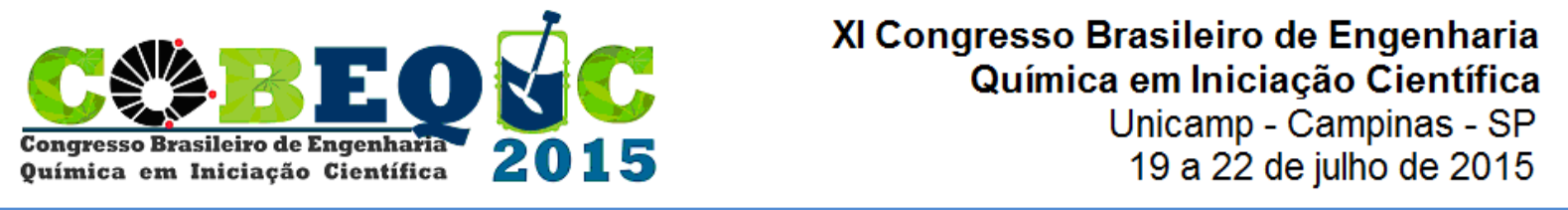

de jorro, variando-se a velocidade e temperatura do ar de secagem, a concentração de leite e o tempo de intermitência na alimentação da mistura leite/graviola ao secador.

\section{MATERIAIS E MÉTODOS}

\subsection{Equipamentos}

O esquema de leito de jorro, utilizado nos experimentos, é representado na Figura 1. O equipamento é constituído de uma coluna cilíndrica com base cônica, construída em aço inoxidável com visores em acrílico. Acoplado à coluna tem-se um ciclone para promover a separação entre o pó e o ar.

Figura 1 - Esquema do Leito de Jorro

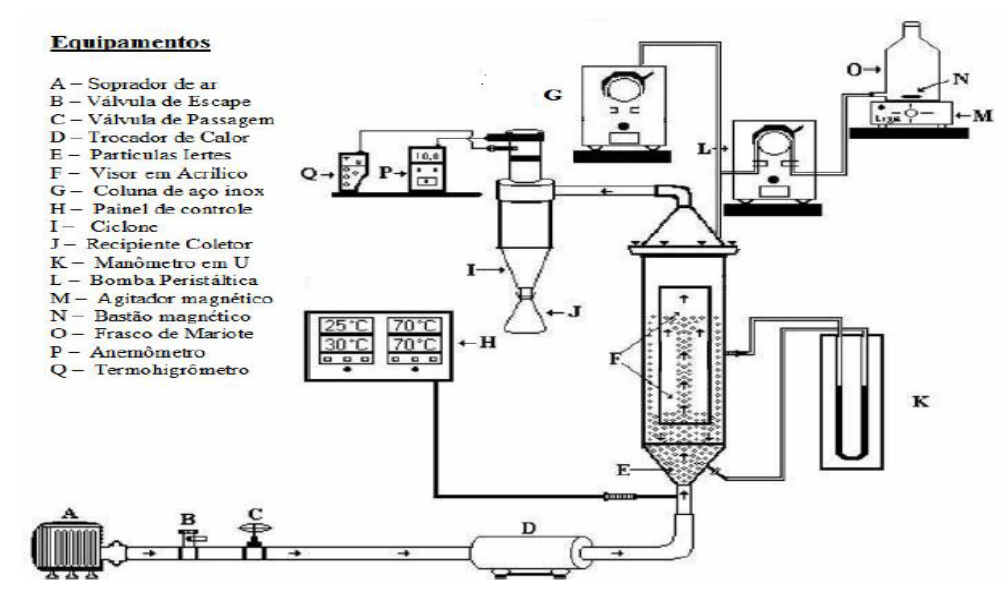

\subsection{Metodologia Experimental}

As misturas foram preparadas de acordo com o ensaio a ser realizado. Trabalhou-se com proporções de 30, 40 e $50 \%$ em peso de leite. Em todos os ensaios a alimentação da mistura foi atomizada e intermitente com uma vazão fixa de $7 \pm 0,8 \mathrm{~mL} / \mathrm{min}$. Foi fixado um total de 6 alimentações por ensaio, com duração de 6 minutos, respeitando sempre os tempos de parada estabelecidos para cada ensaio (4, 6 e $8 \mathrm{~min}$ ), mantendo-se assim uma massa alimentada média em todos os ensaios de $245,35 \pm 28,52 \mathrm{~g}$. A carga de inerte utilizada no secador foi de 2500 g. O sistema de alimentação só era acionado quando ocorria a estabilização da temperatura e umidade relativa da corrente de ar na saída do ciclone. Durante o período de secagem foram coletados dados de temperatura e umidade relativa do ar na saída do ciclone em intervalos de 2 minutos.

\subsection{Metodologias de Cálculos}

Com os dados de umidade relativa e temperatura de bulbo seco do ar de exaustão, determinou-se através das cartas psicrométricas a umidade absoluta do ar. A partir da umidade absoluta e com a temperatura de bulbo seco do ar de entrada, as demais propriedades do ar alimentado foram determinadas: umidade relativa, umidade de saturação, temperatura de 
bulbo úmido, massa específica e entalpia específica. Utilizando-se as cartas psicrométricas, foram também obtidas todas as propriedades do ar na saída do secador necessárias para determinação das taxas de secagem e balanços de massa e energia no secador;

A vazão mássica de ar isento de umidade (Ws) foi calculada a partir da Equação (1) com os dados psicrométricos do ar na saída do secador e da velocidade do ar no jorro.

$$
W_{s}=\frac{\pi D_{c}^{2} v \rho_{g s}}{4\left(U_{g s}+1\right)}
$$

A partir do balanço de massa do ar isento de umidade no secador, foram calculadas as taxas de secagem pela equação 2 .

$$
K=W_{s}\left(U_{g s}-U_{g e}\right)
$$

O calor perdido para o ambiente foi estimado a partir do balanço de entalpia no secador, representado na Equação (3).

$$
W_{g e} I_{g e}+W_{p o l p a} C_{p M} T_{o}=W_{g s} I_{g s}+W_{p o} C_{p p o} T_{g s}+Q_{p}
$$

O calor específico do leite bovino foi consultado na literatura $(3,93 \mathrm{~kJ} / \mathrm{kg} . \mathrm{K})$. O calor específico da polpa e pó da graviola foram estimados a partir de correlações da literatura, levando-se em consideração o teor de umidade presente (SWEAT, 1994).

O calor gasto na evaporação foi calculado pela Equação (4), sendo a entalpia de vaporização da água estimada na temperatura de bulbo úmido do ar na saída do secador.

$$
Q_{e v}=K \Delta H_{V}
$$

Definiu-se a eficiência térmica pela Equação (5).

$$
\operatorname{Efic}_{T}=\frac{Q_{e v}}{Q_{e v}+Q_{p}} 100
$$

Para o cálculo da saturação relativa foi utilizada a equação 6.

$$
\% \operatorname{Sat}_{A r}=\frac{U_{\text {real }}}{U_{\text {Sat }}} 100
$$

\section{RESULTADOS E DISCUSSÕES}

As condições operacionais mantidas em todos os ensaios, assim como os resultados relativos às taxas de secagem, eficiência térmica e saturação relativa e temperatura do ar de exaustão são exibidos na Tabela 1 . 
Tabela 1 - Condições experimentais e resultados da taxa de secagem. Eficiência térmica e saturação relativa do ar de exaustão

\begin{tabular}{ccccccccc}
\hline & $\begin{array}{c}\mathrm{X}_{\mathrm{L}} \\
(\%)\end{array}$ & $\begin{array}{c}\mathrm{T} \\
\left({ }^{\circ} \mathrm{C}\right)\end{array}$ & $\begin{array}{c}\mathrm{tint} \\
(\mathrm{min})\end{array}$ & $\begin{array}{c}\mathrm{Vc} \\
(\mathrm{m} / \mathrm{s})\end{array}$ & $\begin{array}{c}\mathrm{K} \\
(\mathrm{g} / \mathrm{s})\end{array}$ & $\begin{array}{c}\text { Efic } \\
(\%)\end{array}$ & $\begin{array}{c}\text { Tgs } \\
\left({ }^{\circ} \mathrm{C}\right)\end{array}$ & $\begin{array}{c}\text { Sat Ar } \\
(\%)\end{array}$ \\
\hline 1 & 30 & 70 & 10 & 0,93 & 0,083 & 38,49 & 55,24 & 11,83 \\
2 & 50 & 70 & 10 & 0,93 & 0,142 & 60,38 & 52,39 & 17,79 \\
3 & 30 & 90 & 10 & 0,93 & 0,056 & 20,22 & 65,98 & 4,88 \\
4 & 50 & 90 & 10 & 0,93 & 0,091 & 27,86 & 65,41 & 6,87 \\
5 & 30 & 70 & 14 & 0,93 & 0,092 & 44,65 & 54,10 & 12,59 \\
6 & 50 & 70 & 14 & 0,93 & 0,1 & 45,43 & 54,17 & 7,02 \\
7 & 30 & 90 & 14 & 0,93 & 0,084 & 29,41 & 68,76 & 5,66 \\
8 & 50 & 90 & 14 & 0,93 & 0,081 & 33,62 & 68,30 & 4,36 \\
9 & 30 & 70 & 10 & 1,16 & 0,094 & 41,8 & 54,69 & 10,61 \\
10 & 50 & 70 & 10 & 1,16 & 0,102 & 55,07 & 55,78 & 12,71 \\
11 & 30 & 90 & 10 & 1,16 & 0,116 & 22,4 & 69,01 & 3,84 \\
12 & 50 & 90 & 10 & 1,16 & 0,07 & 19,87 & 68,68 & 5,10 \\
13 & 30 & 70 & 14 & 1,16 & 0,045 & 16,86 & 56,81 & 4,93 \\
14 & 50 & 70 & 14 & 1,16 & 0,098 & 49,83 & 55,14 & 12,49 \\
15 & 30 & 90 & 14 & 1,16 & 0,067 & 16,82 & 68,32 & 4,25 \\
16 & 50 & 90 & 14 & 1,16 & 0,066 & 21,99 & 70,50 & 3,80 \\
17 & 40 & 80 & 12 & 1,04 & 0,083 & 33,39 & 61,12 & 7,08 \\
18 & 40 & 80 & 12 & 1,04 & 0,104 & 29,33 & 62,51 & 9,10 \\
19 & 40 & 80 & 12 & 1,04 & 0,081 & 28,71 & 62,14 & 7,36 \\
\hline
\end{tabular}

As taxas de calor em função do tempo, para os ensaios 7 e 6, são representadas nas figuras 2 e 3 respectivamente. $\mathrm{O}$ comportamento oscilatório das curvas representa muito bem a intermitência do processo onde o calor gasto na evaporação atinge picos durante a alimentação e se reduz a valores quase nulos quando a alimentação é suspensa. Conforme se observa no ensaio 7 realizado no nível mais alto de temperatura, as taxas de calor perdido são muito altas quando comparadas as taxas de calor gasto na evaporação. Comparando o ensaio 7 com o 6 observa-se que a condições de maior concentração de leite e menor temperatura contribuíram para diminuir o calor perdido e aumentar o calor gasto na evaporação.

Figura 2 - Calor de evaporação e calor perdido ao longo da secagem (Ensaio $7-\mathrm{X}_{\mathrm{L}}=30 \%$, Tge $=90{ }^{\circ} \mathrm{C}, \mathrm{t}_{\text {int }}=14 \mathrm{~min}, \mathrm{v}_{\mathrm{c}}=0,93 \mathrm{~m} / \mathrm{s}$ )

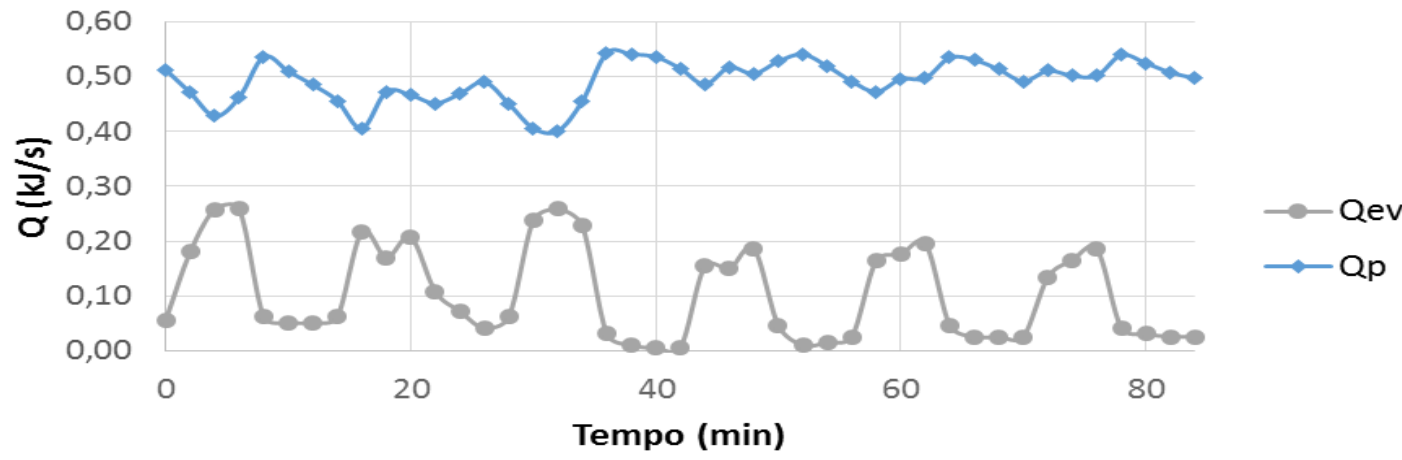


Figura 3 - Calor de evaporação e calor perdido ao longo da secagem (Ensaio $6-\mathrm{X}_{\mathrm{L}}=50 \%$,

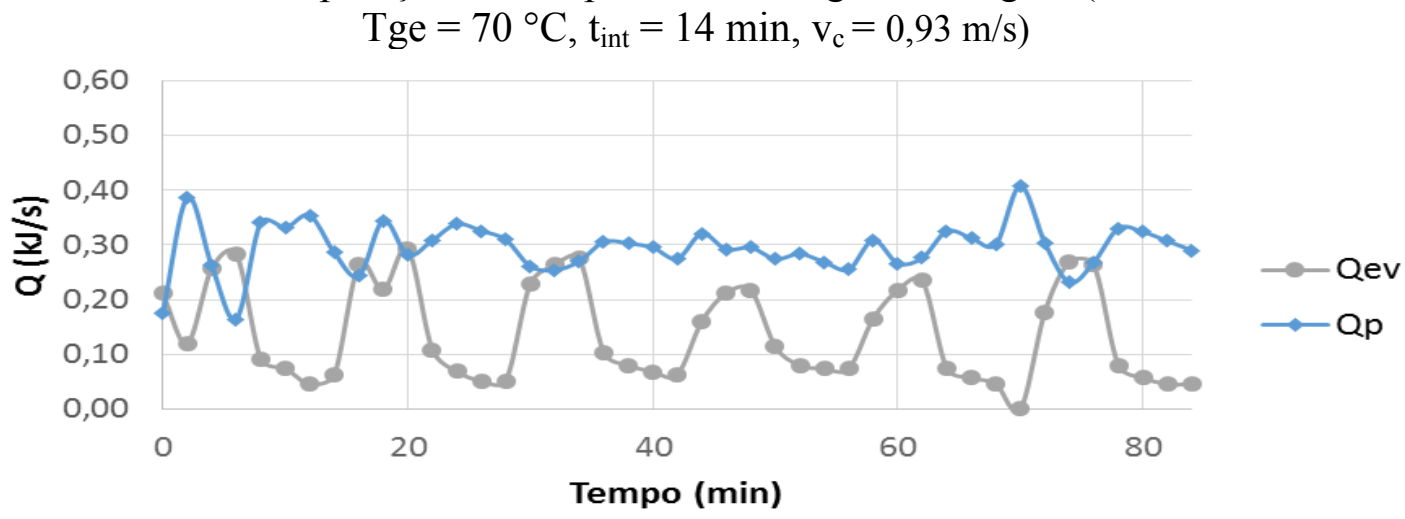

Na Figura 4 encontram-se os valores médios das taxas de calor gasto na evaporação da água e perdido para o ambiente em cada experimento.

Figura 4 - Taxas médias do calor perdido e gasto na evaporação de água

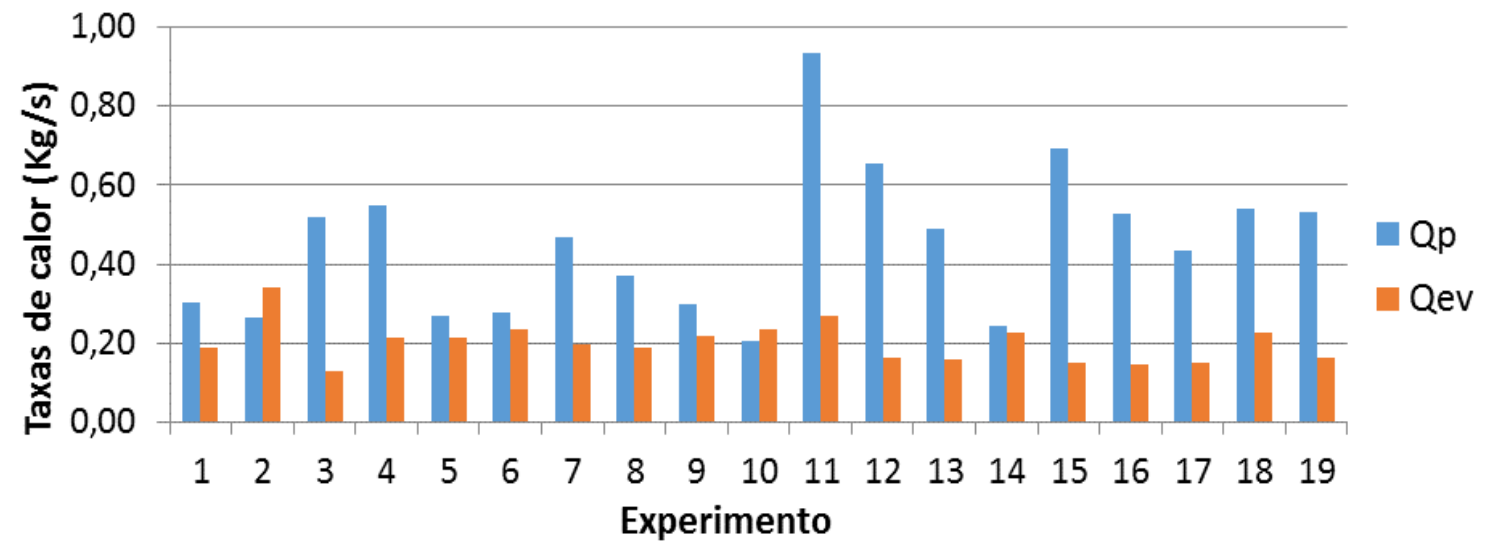

Em todos os experimentos verifica-se que a temperatura do ar de exaustão é elevada e ainda apresenta um elevado potencial energético, uma vez que pouco calor é gasto na evaporação da água. Todavia, para se analisar o seu potencial para secagem é necessário se observar sua condição de saturação. Desta forma foi calculada a saturação relativa do mesmo, ou seja, a razão entre a sua umidade absoluta e a umidade absoluta nas condições de saturação. Na Tabela 1 observa-se que em todos os ensaios a saturação relativa do ar de exaustão é inferior a $20 \%$, o que pode garantir o seu reaproveitamento tanto na forma de reciclo como sua possível utilização em outra linha de secagem, devendo-se, entretanto considerar a necessidade de se introduzir um filtro para separação de finos presentes no ar reciclado.

Com respeito à eficiência térmica do secador, os valores observados na Tabela 1 são baixos e na grande maioria inferiores a $50 \%$. Ressalta-se o experimento 2 com a maior eficiência térmica $(60,38 \%)$, realizado nas condições de maior concentração de leite, temperatura e velocidade do ar mais baixas e tempo de intermitência mais curto. 


\section{CONCLUSÃO}

A eficiência térmica do processo atingiu um máximo de 60,38 \%, observando-se elevadas perdas de calor para o ambiente e o ar de exaustão bastante aquecido e com potencial para ser utilizado como fonte térmica. As maiores eficiências foram observadas em condições de menor vazão e temperatura do ar, curto tempo de intermitência e para as misturas com maior concentração de leite. Estes resultados são compatíveis com os processos de transferência convectiva de calor e massa, predominantes na secagem de pastas em leito de jorro e são tecnicamente importantes, visto que as condições de vazão e temperatura do ar que promoveram maior eficiência correspondem às que demandam menor consumo de energia.

\section{NOMENCLATURA}

\begin{tabular}{llll} 
Q & Calor & \multicolumn{2}{l}{} \\
$\mathrm{Cp}$ & Capacidade calorífica & Subscrito & \\
$\rho$ & Massa específica $\left[\mathrm{g} / \mathrm{cm}^{3}\right]$ & $\mathrm{C}$ & coluna \\
Efic & Eficiência & ev & evaporação \\
$\mathrm{I}$ & Entalpia & ge & gás na entrada \\
$\Delta \mathrm{Hv}$ & Entalpia de vaporização & grav & graviola \\
$\mathrm{X}$ & Fração $[\%]$ & $\mathrm{gs}$ & gás na saída \\
$\mathrm{Sat}$ & Saturação & int & Intermitência \\
$\mathrm{K}$ & Taxa de secagem $[\mathrm{g} / \mathrm{s}]$ & $\mathrm{jm}$ & jorro mínimo \\
$\mathrm{T}$ & Temperatura $\left[{ }^{\circ} \mathrm{C}\right]$ & $\mathrm{L}$ & Leite \\
$\mathrm{t}$ & Tempo $[\mathrm{min}]$ & $\mathrm{M}$ & mistura \\
$\mathrm{U}$ & Umidade do ar $[\%]$ & $\mathrm{p}$ & perdido \\
$\mathrm{V}$ & Velocidade do $\operatorname{ar}[\mathrm{m} / \mathrm{s}]$ & $\mathrm{pgrav}$ & polpa de graviola \\
$\mathrm{W}$ & Vazão $[\mathrm{g} / \mathrm{s}]$ & $\mathrm{s}$ & Seco \\
$\mathrm{V}$ & Volume & $\mathrm{T}$ & térmica
\end{tabular}

\section{REFERENCIAS}

CRUZ, W. F. Obtenção da polpa de goiaba (Psidium guajava L.) em pó pelo método de secagem de espuma. 2013. 93f. Dissertação (Mestrado em Ciência e tecnologia dos Alimentos). Universidade Federal de Viçosa - Programa de pós-Graduação em Ciência e Tecnologia de Alimentos. Minas Gerais, Viçosa.

MEDEIROS, M. F. D. Influência da composição química dos materiais no desempenho do processo de secagem de polpas de frutas em leito de jorro. 2001. 247f. Tese (Doutorado em Engenharia Química) - Faculdade de Engenharia Química, Universidade Estadual de Campinas, Campinas.

SWEAT, V.E. Thermal Porperties of Foods. In: RAO, M.A., RIZVI, S.S.H. Engineering Properties of Foods. Marcel Dekker Inc, NY, 1986. Apud: VIRENDRA, K.B. SINGH, A.K., SINGHY. Prediction of Thermal Conductivity of Fruit Juices by Thermal Resistence Model, Jornal of Food Science, v. 54, n. 4, p. 1007-1012, 1989. 